Article

\title{
Comparative Study on the Antioxidant and Anti-Toxoplasma Activities of Vanillin and Its Resorcinarene Derivative
}

Claudio B. S. Oliveira ${ }^{1}$, Ywlliane S. R. Meurer ${ }^{1,2}$, Marianne G. Oliveira ${ }^{1}$, Wendy M. T. Q. Medeiros ${ }^{3}$, Francisco O. N. Silva ${ }^{3}$, Ana C. F. Brito ${ }^{3}$, Daniel de L. Pontes ${ }^{3}$ and Valter F. Andrade-Neto ${ }^{1, *}$

1 Laboratory of Malaria and Toxoplasmosis Biology/LABMAT, Department of Microbiology and Parasitology, Bioscience Center, Federal University of Rio Grande do Norte, Av. Salgado Filho, s/n, Lagoa Nova, Natal/RN, CEP 59078-970, Brazil

2 Memory Studies Laboratory, Physiology Department, Bioscience Center, Federal University of Rio Grande do Norte, Av. Salgado Filho, s/n, Lagoa Nova, Natal/RN, CEP 59078-970, Brazil

3 Laboratory of Coordination Chemistry and Polymers, Institute of Chemistry, Federal University of Rio Grande do Norte, Av. Salgado Filho, s/n, Lagoa Nova, Natal/RN, CEP 59078-970, Brazil

* Author to whom correspondence should be addressed; E-Mail: aneto@cb.ufrn.br; Tel.: +55-84-3215-3437; Fax: +55-84-3211-9210.

Received: 7 February 2014; in revised form: 26 April 2014 / Accepted: 28 April 2014 / Published: 7 May 2014

\begin{abstract}
A resorcinarene derivative of vanillin, resvan, was synthesized and characterized by spectroscopic techniques. We measured the cytotoxicity (in vivo and in vitro), antioxidant and anti-Toxoplasma activities of vanillin and the resorcinarene compound. Here we show that vanillin has a dose-dependent behavior with $\mathrm{IC}_{50}$ of $645 \mu \mathrm{g} / \mathrm{mL}$ through an in vitro cytotoxicity assay. However, we could not observe any cytotoxic response at higher concentrations of resvan $\left(\mathrm{IC}_{50}>2,000 \mu \mathrm{g} / \mathrm{mL}\right)$. The in vivo acute toxicity assays of vanillin and resvan exhibited a significant safety margin indicated by a lack of systemic and behavioral toxicity up to $300 \mathrm{mg} / \mathrm{kg}$ during the first $30 \mathrm{~min}, 24 \mathrm{~h}$ or 14 days after administration. The obtained derivative showed greater antioxidative activity $(84.9 \%)$ when comparing to vanillin $(19.4 \%)$ at $1,000 \mu \mathrm{g} / \mathrm{mL}$. In addition, vanillin presents anti-Toxoplasma activity, while resvan does not show that feature. Our findings suggest that this particular derivative has an efficient antioxidant activity and a negligible cytotoxic effect, making it a potential target for further biological investigations.
\end{abstract}

Keywords: vanillin; resorcinarene; antioxidant; anti-Toxoplasma 


\section{Introduction}

Toxoplasma gondii is an intracellular protozoan of the phylum Apicomplexa. It is one of the most widespread parasites in Nature, which can infect a wide range of host species, including one-third of the World's human population [1]. As an opportunistic human pathogen, T. gondii may cause severe disease in immunocompromised individuals, such as HIV positive patients, and congenitally infected newborns [2]. In these patients, upon reactivation of a latent infection, this parasite can cause retinochoroiditis or CNS lesions [3,4].

Infection can occur congenitally or it can be acquired through any of the forms of the parasite, such as oocysts ingested from contaminated food with cat feces and across cysts in undercooked meat. In addition, it can also be transmitted through acute maternal infection during pregnancy $[5,6]$.

Nowadays, toxoplasmosis is being treated with a combination of sulfadiazine and pyrimethamine, both key enzyme inhibitors in the biosynthesis of pyrimidines in T. gondii [7]. However, these treatments may cause adverse reactions, including suppression of the bone marrow, teratogenic effects in the first trimester of pregnancy and sulfadiazine hypersensitivity $[5,8,9]$. Thus, there is an increasing need for new drugs and treatment regimens against toxoplasmosis. Manipulations of natural products mainly derived from plants and insects might be a good choice in order to diminish the damage caused by conventional treatment or even improve treatment outcome.

Cultural knowledge about medicinal plants handling represent a vital role in the discovery of novel natural products with chemotherapeutic properties [10-15]. The use of medicinal herbs in developed countries kept its popularity due to historical and cultural reasons even with the access to modern medicine for most of the population [16]. On the other hand, in the developing countries, $65 \%-80 \%$ of the population depends exclusively on the medicinal plants for basic healthcare. It corresponds to $80 \%$ of the population in Africa, $71 \%$ in Chile, $40 \%$ in Colombia and $80 \%$ in Brazil $[17,18]$.

Thereby, vanillin (4-hydroxy-3-methoxybenzaldehyde, Figure 1), a compound isolated from the bean and pod of tropical vanilla orchid is widely used in the food and beverage industry and is responsible for the characteristic vanilla flavor. This substance is also relevant for the synthesis of different agrochemicals, antifoaming and pharmaceutical products [19].

Figure 1. Vanillin structure.

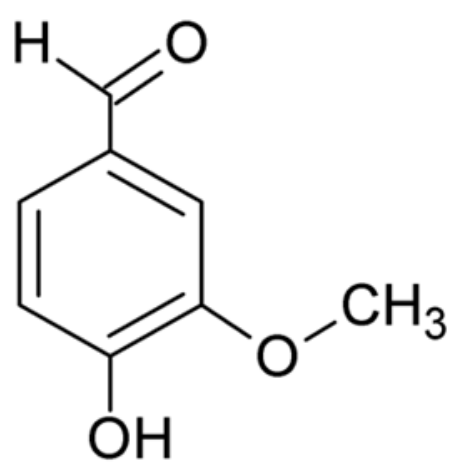

Besides its industrial and food application this compound has been the subject of several scientific investigations in the last years, such as the identification of antioxidant properties [20], antimicrobial 
activity [21-23] as well as antimutagenic [24,25] and anticarcinogenic actions [26]. Conversely, vanillin may also induce oxidative stress in yeast cells [27].

Part of these biological properties can be attributed to the fact that vanillin is a phenolic compound. The antioxidant activity of phenols is attributed to their ability to scavenge free radicals. Other important phenol compounds include the dihydroxybenzenes, and its derivatives [28].

Indeed, vanillin presents different functional groups, including ether and aldehyde moieties, besides the phenolic group. The presence of a methoxy group adjacent to the phenol hydroxyl gives origin to a group of compounds isolated from plants called vanilloids, which includes substances such as vanillin, eugenol and capsaicin [29].

The presence of the aldehyde functional group turns possible the synthesis of vanillin derivatives by condensation reactions. It is known from the works of Niederl and Vogel [30] that the reaction of aldehyde with resorcinol (1,3-dihydroxybenzene) produces macrocyclic structures called resorcinarenes (Figure 2). These structures generally adopt a bowl or vase-like conformation characterized by the presence of a wide upper rim (resorcinol hydroxyl groups) and a narrow lower rim ( $\mathrm{R}$ groups from the starting aldehydes). This class of compounds is particularly interesting because the structural organization and the presence of moieties with different polarities: polar region due the eight hydroxyl groups in the upper rim and nonpolar region originated by the benzene rings.

The condensation of vanillin and resorcinol (Scheme 1) enables the preparation of the compound C-4-hydroxy-3-methoxyphenylcalix[4]resorcinarene, here identified as resvan (Figure 2), with a large number of phenolic groups.

Figure 2. Resorcinarene general structure.
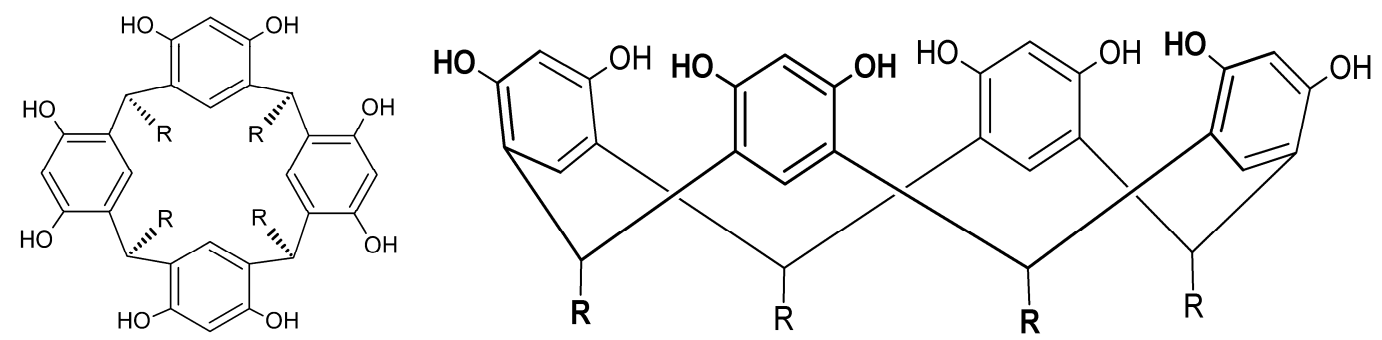

Scheme 1. Resvan synthesis scheme.
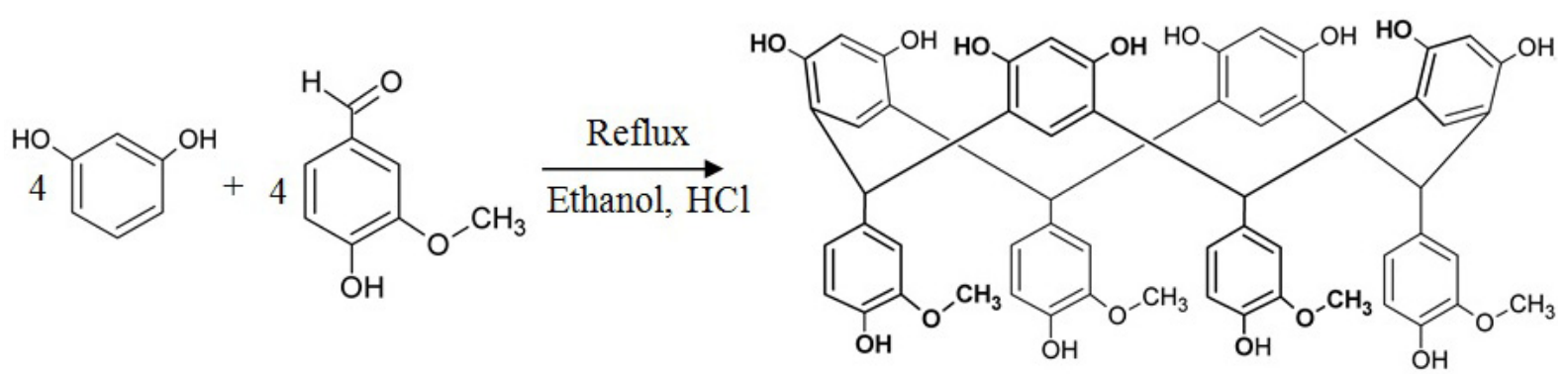

Our interest in studying substances isolated from plants and its derivatives, and knowledge of antiprotozoal activity of the vanilloids compounds [31] led us to examine the antioxidant properties of the resorcinarene synthesized from vanillin and to evaluate the toxicity in vivo and in vitro and the antioxidant and the anti-Toxoplasma activity of this compound compared to vanillin. 


\section{Results and Discussion}

\subsection{Infrared Analysis}

The assignments of the signals observed in the infrared (IR) vibrational spectra of resvan were made in a qualitative form by comparison with similar data reported in the literature [32] for related compounds and with the signals observed in the vibrational spectra of the starting materials vanillin and resorcinol (Table 1).

Table 1. Infrared spectra and assignments of the main bands $\left(\mathrm{cm}^{-1}\right)$ of the compounds resorcinol, vanillin and resvan.

\begin{tabular}{cccc}
\hline Assignment & Resorcinol & Vanillin & Resvan \\
\hline$v \mathrm{O}-\mathrm{H}$ (phenol) & 3447 & 3447 & 3411 \\
$\nu \mathrm{C}-\mathrm{H}$ (aromatic) & 3012 & 3013 & 3008 \\
$\nu \mathrm{C}-\mathrm{H}$ (aldehyde) & & 2855 & \\
$\nu \mathrm{C}=\mathrm{O}$ (aldehyde) & & 1666 & \\
$\nu \mathrm{C}-\mathrm{C}$ (benzene) & 1616 & 1596 & 1616 and 1518 \\
$\nu \mathrm{CH}_{3}$ (methoxy) & & 1463 & 1463 \\
$\delta \mathrm{CH}$ (methine bridge) & & & 1430 \\
$\nu \mathrm{C}-\mathrm{CHO}$ (aldehyde) & & 1265 & \\
$\nu \mathrm{C}-\mathrm{O}$ (ether) & & 1200 & 1204 \\
$\delta \mathrm{CH}$ (methoxy) & & 1172 & \\
$\nu \mathrm{C}-\mathrm{OH}$ & 1150 & 1155 & 1154 \\
$\delta \mathrm{CCH}$ (in-plane) & & 1123 & 1123 \\
$\nu \mathrm{O}-\mathrm{CH}$ & 1028 & 1030 \\
$\delta \mathrm{C}-\mathrm{C}-\mathrm{CHO}$ (out-of-plane) & & 732 & \\
$\delta \mathrm{C}-\mathrm{C}=\mathrm{O}$ (in-plane) & & 588 & \\
\hline
\end{tabular}

The IR spectrum of the compound has a broad absorption at $3411 \mathrm{~cm}^{-1}$ related to phenolic hydroxyl stretching $(\mathrm{vOH})$ of the upper and lower rim. Absorptions at 1616 and $1518 \mathrm{~cm}^{-1}$ are assigned to C-C stretching of the aromatic rings present in the structure. As resvan formation involves the condensation of the vanillin aldehyde group with resorcinol, the infrared peaks related to the aldehyde functional group are no longer expected in the IR spectrum. This result was confirmed since the aldehyde bands at $1666(\mathrm{vC}=\mathrm{O}), 1267(\mathrm{vC}-\mathrm{CHO}), 734\left(\delta \mathrm{C}-\mathrm{CO}\right.$ out-of-plane) and $590 \mathrm{~cm}^{-1}$ ( $\delta \mathrm{C}-\mathrm{CO}$ in-plane) present in the vanillin IR spectrum were not observed in the resorcinarene spectrum [33]. On the other hand, the IR retains the peaks related to the methoxy group also observed in vanillin, however with a slight variation in wavenumber. The peak corresponding to the methine carbon of the macrocyclic structure was observed at $1430 \mathrm{~cm}^{-1}$.

\subsection{Electronic Spectra Analysis}

The electronic spectrum of the resvan in water solution presented two bands at $198(\varepsilon=1.7 \times$ $\left.10^{4} \mathrm{M}^{-1} \mathrm{~cm}^{-1}\right)$ and $288 \mathrm{~nm}\left(\varepsilon=3.5 \times 10^{3} \mathrm{M}^{-1} \mathrm{~cm}^{-1}\right)$, besides two shoulders around $233 \mathrm{~nm}$ and $316 \mathrm{~nm}$ (Figure 3). Spectra of benzene derivatives usually have at least three bands assigned to $\pi-\pi^{*}$ electronic transitions in the UV-Vis region. The resorcinol spectrum shows these bands at 194, 218 and $272 \mathrm{~nm}$. 
Such bands are shifted around $10 \mathrm{~nm}$ to longer wavelength in the vanillin spectrum due to the presence of different chemical groups bonded to the benzene ring. For this substance these bands were observed at 204, 229 and $279 \mathrm{~nm}$. Additionally the presence of a fourth band at $309 \mathrm{~nm}$ assigned to $\mathrm{n}-\pi^{*}$ transitions involving the carbonyl group of the aldehyde substituent can be verified.

The resvan electronic spectrum had a similar trend showing bands in the ultraviolet region at 198, 233 and $288 \mathrm{~nm}$, all assigned to $\pi-\pi^{*}$ transitions, and a shoulder at approximately $316 \mathrm{~nm}$ that extends to the visible region assigned to $n-\pi^{*}$ transitions.

Figure 3. Electronic spectrum in water of resvan $\left(5.5 \times 10^{-5} \mathrm{~mol} \mathrm{~L}^{-1}\right)$ and vanillin $\left(5.8 \times 10^{-5} \mathrm{~mol} \mathrm{~L}^{-1}\right)$.

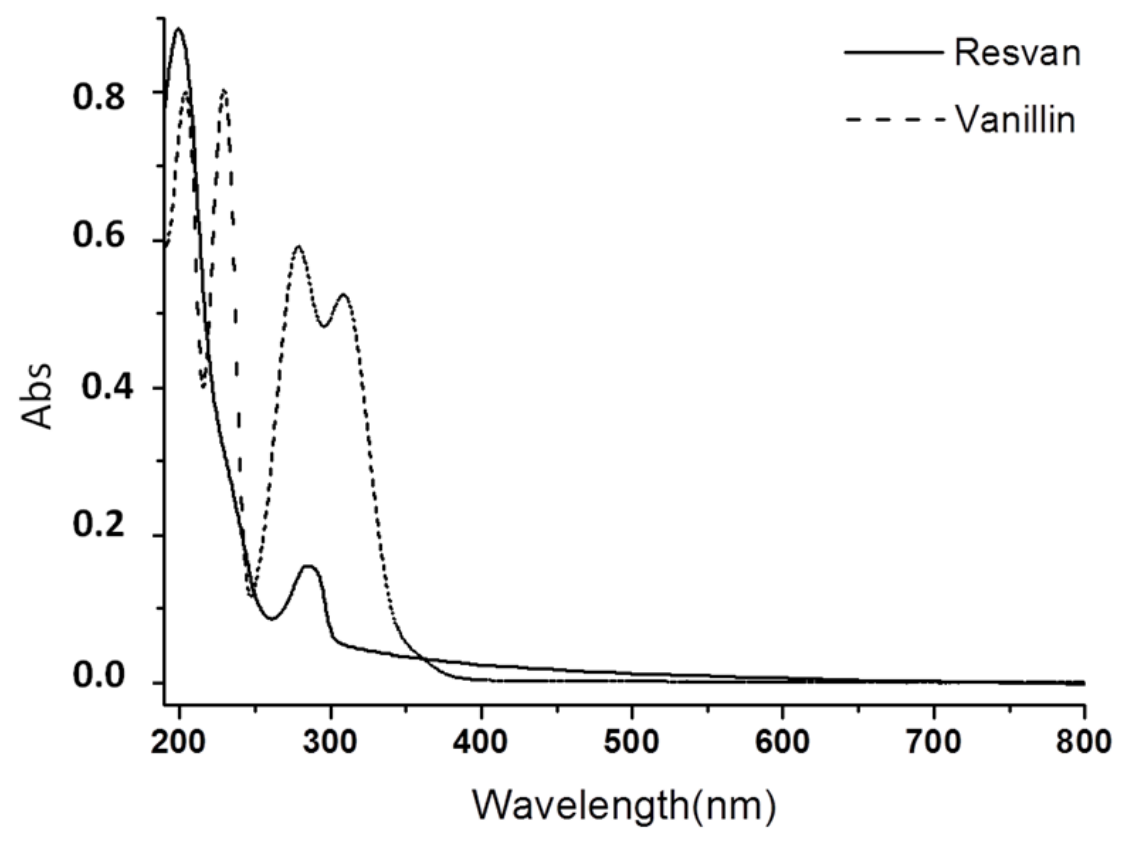

\subsection{Citotoxicity and Acute Toxicity}

The cytotoxicity assay with murine macrophage cells was performed to compare the effect of vanillin and its derivative molecule, resvan (Figure 4). In the cytotoxicity assay analysis, the $T$-test revealed significant differences between resvan and vanillin treatment $(\mathrm{t}=2.692, p=0.0192)$. In the multiple $T$-test, differences between vanillin and resvan treatment were detected for 500, 1,000 and $2,000 \mu \mathrm{g} / \mathrm{mL}$ concentrations. In this test vanillin presented an $\mathrm{IC}_{50}$ of $645 \mu \mathrm{g} / \mathrm{mL}$. In other studies, vanillin shows a dose-dependent activity, where a high concentration induces a reduction of $50 \%$ in cell viability, including tumoral cells [26]. However, no cytotoxic effects were observed when cells were treated with different concentrations of resvan $\left(\mathrm{IC}_{50}>2,000 \mu \mathrm{g} / \mathrm{mL}\right)$, a vanillin derivative. The low cytotoxicity found for vanillin in vitro corroborates the results obtained by other authors for vanillin and the $o$-vanillin isomer [26,34]. The cytotoxicity results obtained suggest compounds vanillin and resvan can be used safely in other tests in order to investigate their biological activity. 
Figure 4. Influence of vanillin and resorcinarene in RAW 264.7 macrophage cell viability after treatment for $24 \mathrm{~h}$. Results are expressed in percentage of control. Three independent experiments are performed in triplicate. ( $^{\#} p<0.001$ compared to 500, 1,000 and $2,000 \mu \mathrm{g} / \mathrm{mLvanillin}$ treatment).

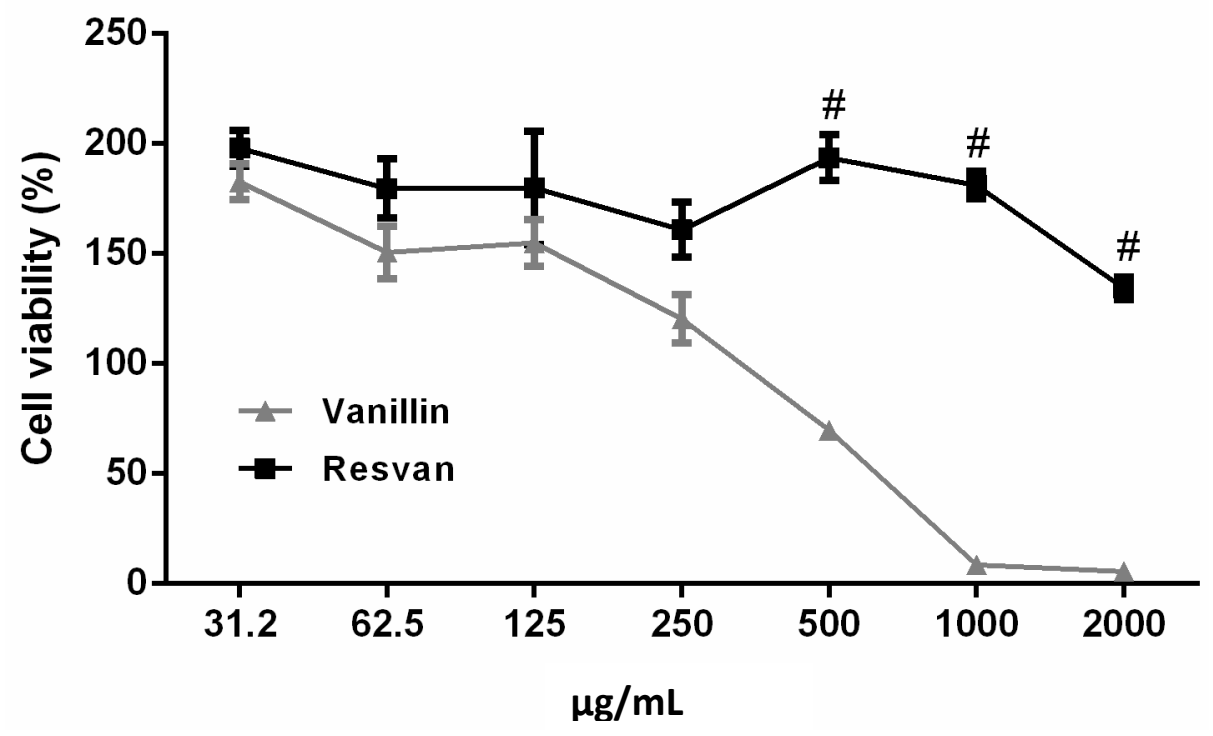

The results suggest better biological activity and altered toxicity properties after molecular alterations in the vanillin structure. Thus, modifications seem to be promising for other biological and chemical studies. The acute toxicity in vivo studies of vanillin and resvan were performed based on OECD guidelines, with modifications [35], where both exhibited a significant safety margin as indicated by a lack of systemic and behavioral toxicity up to $500 \mathrm{mg} / \mathrm{kg}$, that is, no related adverse effects for animals treated with $500 \mathrm{mg} / \mathrm{kg}$ during first $30 \mathrm{~min}, 24 \mathrm{~h}$ and even up to 14 days after administration of chemicals. Thus, the result indicates that resvan had no significant impact regarding the in vivo toxicity when compared to vanillin. Also, no adverse effects were observed in the control group receiving DMSO 8\% (data not shown).

The divergent toxicity (in vivo and in vitro models) presented by vanillin, in relation to resvan, suggests a different metabolic route for this compound. Resvan was nontoxic in both in vivo and in vitro evaluation. This result provides further evidence of involvement of the liver in biotransformation the vanillin into a nontoxic metabolite.

\subsection{Antioxidant Activity}

The DPPH method was used to evaluate the antioxidant activity of vanillin and its resorcinarene derivative. It is an appropriate method when radical scavenging abilities of compounds are investigated at room temperature. The measure is widely recognized for this purpose and presents high correlation with other methods such as ferric reducing power and the total phenolics content [36,37]. The results suggest that resvan presented an excellent free radical scavenging activity, $84.9 \%$, when compared to vanillin, $19.4 \%$. The resvan activity was similar to that observed for the ascorbic acid, $93.6 \%$, used as a standard product for the assay (Figure 5). 
Figure 5. Antioxidant activity of ascorbic acid, vanillin and resvan assessed by DPPH radical scavenging activities method $\left(^{\#} p<0.001\right.$ compared to $125 \mu \mathrm{g} / \mathrm{mL}$ Ascorbic acid treatment; ${ }^{\circ} p<0.01$ compared to $500 \mu \mathrm{g} / \mathrm{mL}$ ascorbic acid treatment; $* p<0.05$ compared to $1,000 \mu \mathrm{g} / \mathrm{mL}$ ascorbic acid treatment).

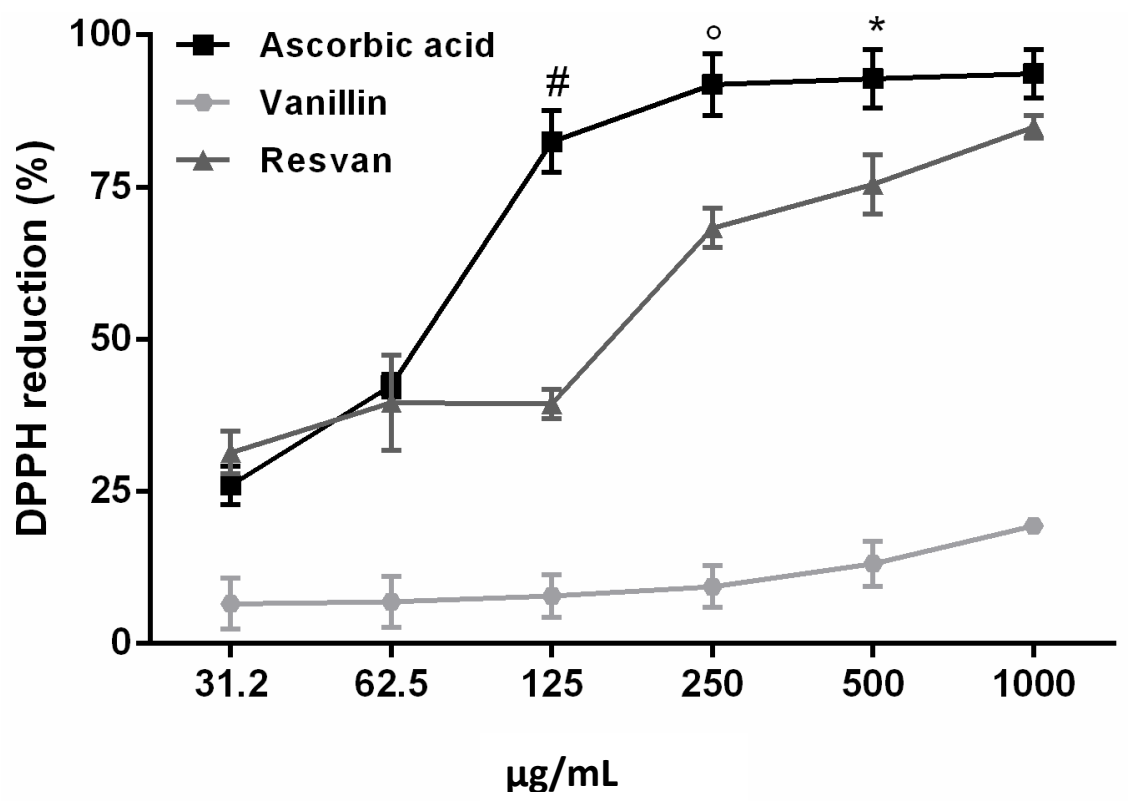

The reducing property indicates that the antioxidant compounds are electron donors and can reduce the oxidized intermediates of the lipid peroxidation process, so that they can act as primary and secondary antioxidants [36].

The reduction of DPPH as indicated is followed by monitoring the decrease in its absorbance at a characteristic wavelength during the reaction. In its radical form, DPPH absorbs at $517 \mathrm{~nm}$, but upon reduction by an antioxidant $(\mathrm{AH})$ or a radical species ( $\mathrm{Re})$, the absorption disappears [37]. From the results obtained in the present study, it is evident that the interaction of a potential antioxidant with

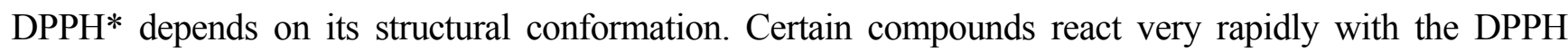
reducing the number of DPPH molecules which corresponding to the number of available hydroxyl groups. However, for the majority of the compounds tested the mechanism seems to be more complex [38,39].

In this paper, the results corroborate to those obtained in other studies [37,40,41]. Here, have attempted to explain the results obtained using the DPPH method for the compound as well as ascorbic acid. Even if antioxidant activity is extremely beneficial for scavenging free radicals, it's even more important in cell signaling and in defense against pathogens, an can be very harmful as they react with several important molecules, altering the structure and function of proteins and initiating the process of oxidation of fatty acids, which are the cell membrane lipids [42].

This higher antioxidant activity found in resvan is extremely relevant especially when compared to vanillin, already recognized as an antioxidant substance [20,43] and resvan has more activity. This effect is possibly due to the higher number of phenolic hydroxyls found in resvan (Figure 2) compared to vanillin (Figure 1). These phenolic hydroxyls probably act in scavenging of the free radicals. Another advantage of this result is that the resvan, beyond its improved antioxidant activity, also showed lower toxicity for cultured macrophages. Hence, the structural change generated an efficient less toxic and more active compound. These encouraging data were expected considering that the 
chemical structure of resvan presents several hydroxyl groups, which could act in the clearance of free radicals in the DPPH assay.

\subsection{Determination of in Vivo Antiprotozoal Activity of the Compounds}

Mice were infected with T. gondii ME49 strain and treated for six consecutive days. The 30-day observation period showed that mortality only occurred in the infected and untreated control groups (19th and 23th days) and in mice treated orally with resvan (10th day). The groups of animals treated with vanillin and sulfadiazine displayed a higher survival trend compared to the untreated control group (Figure 6), evidencing the antitoxoplasmic activity of these regimens. Vanillin also caused a reduction in loss body weight in mice, indicating also its contribution to reduce the disease morbidity (Figure 7).

Figure 6. Survival curves of Swiss female mice after infection with the ME49 strain of T. gondii and treated with sulfadiazine $(200 \mathrm{mg} / \mathrm{Kg})$, resvan $(500 \mathrm{mg} / \mathrm{Kg})$ or vanillin $(500 \mathrm{mg} / \mathrm{Kg})$.

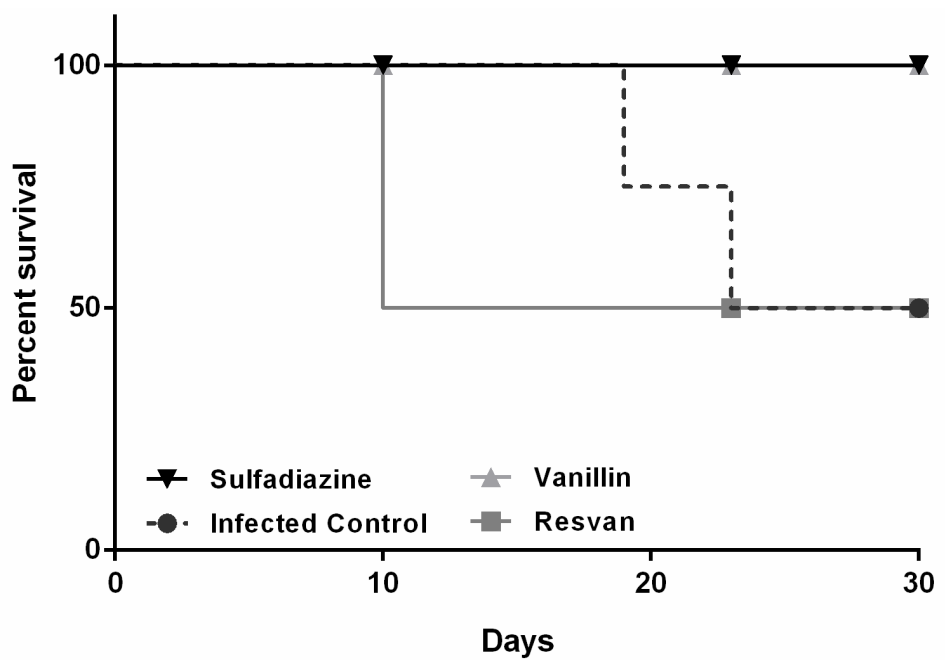

Figure 7. Change in body weight in Swiss mice infected with 25 cysts of $T$. gondii ME49 strain and treated with sulfadiazine $(200 \mathrm{mg} / \mathrm{Kg})$, resvan $(500 \mathrm{mg} / \mathrm{Kg})$ or vanillin $(500 \mathrm{mg} / \mathrm{Kg})$.

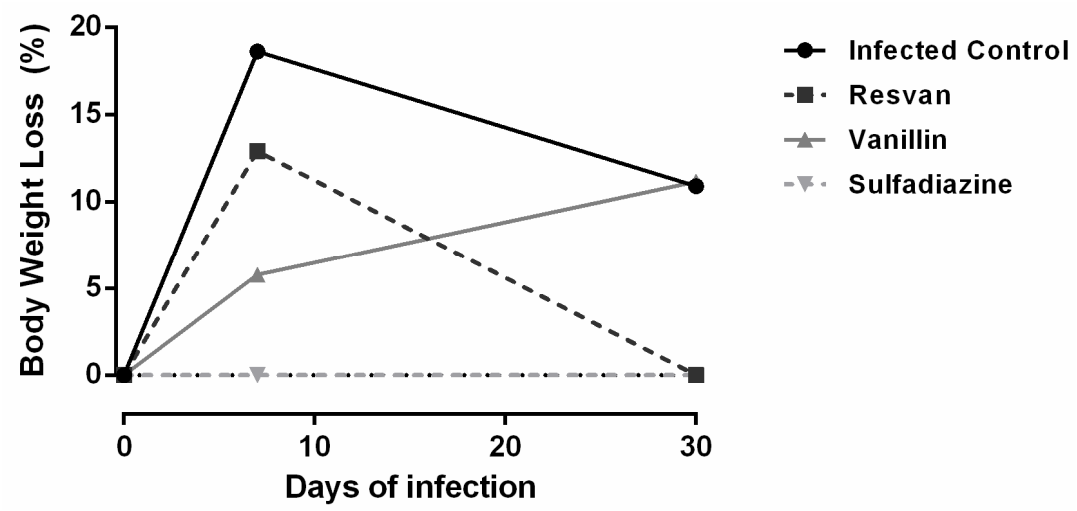

The survival time for the vanillin and sulfadiazine groups was significantly longer $(p<0.05)$ compared to the infected control group. Treatment of the mice with vanillin significantly increased 
their survival rate on the 30th day after challenge by approximately $50 \%$ compared with the infected control group $(p<0.05)$. These data are similar to those observed with Artemisia annua tea infusion [44], which produced a similar effect to that achieved with the reference drug, sulfadiazine, in reducing morbidity (Figure 8) and mortality (Figure 7), but in this work brains cysts were increased in groups treated with vanillin-4,533 cysts, compared to sulfadiazine treatment group-4 cysts (Figure 8). For the number of cysts in mice brain, one way ANOVA analysis revealed significant differences between treatment groups $[\mathrm{F}(3,12)=5.084, p=0.0168)$. Post hoc analysis revealed an increased number of cysts in mice brains for infected control and vanillin treatments when compared with sulfadiazine treatment. However, no differences between sulfadizine and resvan treatment were detected by the Bonferroni's pos hoc test. The ME49 strain is a better alternative in in vivo antitoxoplasmic activity tests, since it is less virulent, facilitating the chronic phase of infection [45], thereby allowing more time to assess different treatment regimes.

The importance of vanillin in inhibiting the mortality in mice with toxoplasmosis is remarkable. However, it is important to remark that, in the surviving animals, there was an increase in the number of brain cysts, probably due formation of a parasite-stressed environment, important to cyst formation [46-49]. The lower therapeutic efficiency for resvan may be due its larger antioxidant activity, which can inhibit the formation of free radicals essential for the destruction of the parasite [50]. There are no studies that report the action of vanillin or resvan in control of toxoplasmosis, which is unprecedented. There are papers that report several biological activities for vanillin and its derivatives [20-23,26,27,43], however this anti-protozoan activity was only just recently reported among vanilloid compounds [29]. Further studies to assess the antiparasitic effects in vitro are required.

Figure 8. Number of brain cysts in Swiss mice infected with 25 cysts of $T$. gondii ME49 strain and treated with sulfadiazine $(200 \mathrm{mg} / \mathrm{Kg})$, resvan $(500 \mathrm{mg} / \mathrm{Kg})$ or vanillin $(500 \mathrm{mg} / \mathrm{Kg})(* p<0.05$ compared to sulfadiazine treatment).

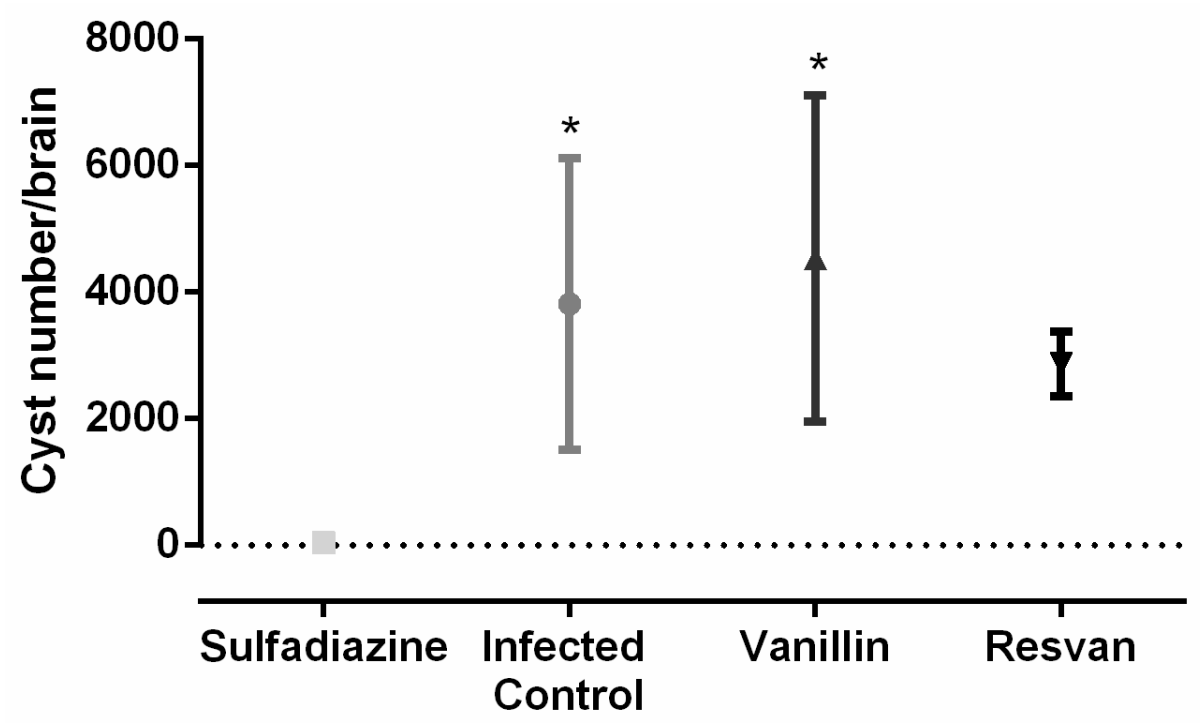




\section{Experimental}

\subsection{Chemicals}

Vanillin and resorcinol were purchased from Vetec Química Fina Ltda - Sigma-Aldrich Corporation (Rio de Janeiro, Brazil). MTT [3-(4,5-dimethyl-2-thiazolyl)-2,5-diphenyl-2H-tetrazolium bromide)] and DPPH (2,2-diphenyl-1-picrylhydrazyl) were purchased from Sigma-Aldrich (St. Louis, MO, USA). All reagents were used without further purification. Other trivial chemicals used were all of analytical grade. Reaction progress was monitored by TLC using Fluka silica gel HF254.

\subsection{Synthesis of C-4-Hydroxy-3-Methoxyphenylcalix [4] Resorcinarene (Resvan)}

The compound was prepared in one-step reaction pathway (Scheme 1) using a similar procedure to that reported by Rose [51]. Vanillin $(0.766 \mathrm{~g}, 5 \mathrm{mmol})$ and resorcinol $(0.552 \mathrm{~g}, 5 \mathrm{mmol})$ were dissolved in ethanol $(30 \mathrm{~mL})$ and to the resulting solution concentrated hydrochloric acid $(0.5 \mathrm{~mL})$ was added dropwise with continuous stirring. The solution was kept $15 \mathrm{~h}$ under reflux and the beige precipitate obtained was filtered, washed with ethanol and dried. Yield: $75 \%$.

\subsection{Apparatus}

Electronic spectra in the ultraviolet and visible (UV-Vis) regions were acquired with a Shimadzu model UV 1800 spectrophotometer using water as solvent. Infrared spectra were obtained in $\mathrm{KBr}$ pellets with a Thermo Nicolet Nexus 470 FT-IR spectrophotometer. When necessary (MTT Method) the optical density (OD) at $570 \mathrm{~nm}$ was determined in a Uv-Vis spectrophotometer (Thermoplate).

\subsection{Cytotoxicity Assay}

For the cytotoxicity assay, an adapted methodology from Tempone [52] was used. RAW 264.7 cells were cultured in Dulbecco's modified Eagle's medium (DMEM; GIBCO Inc., NY, USA) supplemented with $40 \mathrm{mg} / \mathrm{L}$ of gentamicin and 10\% fetal bovine serum (FBS; GIBCO Inc., NY, USA). The cells were incubated in an atmosphere of $5 \% \mathrm{CO}_{2}$ at $37^{\circ} \mathrm{C}$ and were sub-cultured every 5 days.

RAW 264.7 murine macrophage cells were seeded at $1 \times 10^{4}$ cells per well in 96-well microplates and incubated at $37{ }^{\circ} \mathrm{C}$ for $24 \mathrm{~h}$ in the presence of the compounds, dissolved previously in DMSO at a concentration lower than $1 \%$ and twofold serial diluted with DMEM medium to the concentration between $31.2 \mu \mathrm{g} / \mathrm{mL}$ and $2,000 \mu \mathrm{g} / \mathrm{mL}$. The microplates were incubated for $24 \mathrm{~h}$ at $37{ }^{\circ} \mathrm{C}$ in a $5 \% \mathrm{CO}_{2}$ humidified incubator. Control cells were incubated in the presence of dimethylsulfoxide (DMSO) without drugs (1\%).

The viability of the macrophages was determined with the Diphenyltetrazolium (MTT) assay. Initially, MTT $(0.5 \mathrm{mg} / \mathrm{mL})$ was dissolved in Phosphate Buffered Saline (PBS) and sterilized through $0.22 \mu \mathrm{m}$ membranes, and then $100 \mu \mathrm{L} /$ well was added to a 96 -well plate and left at $37^{\circ} \mathrm{C}$ for $3 \mathrm{~h}$. Formazan extraction was performed with DMSO $(200 \mu \mathrm{L} /$ well $)$ at $25^{\circ} \mathrm{C}$, and the (OD) at $570 \mathrm{~nm}$ was determined in a Uv-Vis spectrophotometer. 


\subsection{Animals}

Swiss-Webster albino (6-8 weeks of age) were used for the toxicity and anti-Toxoplasma tests and received water and food ad libitum. In vivo tests were performed using Guidelines for Ethical Conduct in The Care and Use of Animals from the Federal University of Rio Grande do Norte (CEUA, Protocol number 43/2010).

\subsection{Acute Toxicity}

Acute toxicity studies were performed for the compounds following, with modifications, OECD guidelines [35]. Female Swiss mice of 8-12 weeks weighing around 23-25 g were used. Chemicals were orally administered to the animals in a dose of $500 \mathrm{mg} / \mathrm{kg}$. The animals were observed continuously for $2 \mathrm{~h}$ for any symptoms of toxicity (piloerection, weight loss and postural abnormalities) and /or death. They were under observation for further 2 weeks.

\subsection{Scavenging Activity on 1,1-Diphenyl-2-picrylhydrazyl (DPPH) Radicals}

Scavenging activity on 1,1-diphenyl-2-picrylhydrazyl (DPPH) radicals by vanillin and resvan was measured according to the method described by Ye [53], with adaptations, in which decrease in absorbance of reaction mixture containing DPPH and compounds were measured after fixed time interval.

Accordingly, $100 \mu \mathrm{L}$ of vanillin, resvan and ascorbic acid in different concentrations $(31.25 \mu \mathrm{g} / \mathrm{mL}$ up to $1,000 \mu \mathrm{g} / \mathrm{mL})$ were plated with $200 \mu \mathrm{L}$ of DPPH solution $(0.7 \mathrm{mM})$ in each well. The microplates were incubated for $30 \mathrm{~min}$ in room temperature and then the absorbance was measured at $517 \mathrm{~nm}$ in a Uv-Vis spectrophotometer.

Percent scavenger was calculated as follows:

$$
\% \mathrm{~S}=[1-(\mathrm{A} 1 / \mathrm{A} 0)] \times(100 \%)
$$

where A1 corresponds to the absorbance of the samples and A0 is the absorbance of the control.

\subsection{Determination of in Vivo Antiprotozoal Activity of the Compounds}

In vivo tests were performed with female Swiss mice $(n=4)$, as previously described [44]. Initially mice were infected orally with 25 cysts. After $24 \mathrm{~h}$, animals received orally their respectively treatment with a daily dose of vanillin (diluted in distilled water), resvan $(500 \mathrm{mg} / \mathrm{kg}$, diluted in DMSO $8 \%$ ) or sulfadiazine $(200 \mathrm{mg} / \mathrm{kg})$ for 6 days after infection. The animals were observed daily for mortality and morbidity. All surviving animals were euthanized at thirty days of infection for the quantification of the parasite burden in brain tissues.

\subsection{Statistical Analysis}

Data were analysed by Multiple $T$-test or one way analysis of variance (ANOVA) followed Bonferroni's pos hoc test when appropriate. The Mantel-Cox log-rank test was performed for survival time analysis using GraphPad Prism version 6.0 for Windows (GraphPad Software, La Jolla, CA, USA). 


\section{Conclusions}

Thus, we can conclude that the chemical modification proposal was efficient in increasing the antioxidant and reduce cytotoxicity, but just vanillin presented anti-Toxoplasma activity. These results show this derivative attractive as an efficient antioxidant with negligible cytotoxic effects and potentially interesting for further biological trials. We also highlight the importance of the vanillin acting to combat parasite infections.

\section{Acknowledgments}

This work was supported by grants (476637/2012-0 and 301837/2012-0) from National Counsel of Technological and Scientific Development (CNPq).

\section{Author Contributions}

C.B.S.O; D.L.P. and V.F.A.N. participated in the conception and design of the study. C.B.S.O; Y.S.R.M. and M.G.O. carried out the bulk of the biological assays. W.M.T.Q.M.; O.A.O.; F.O.N.S.; A.C.F.B. and D.L.P. carried out the structural changes in compounds and chemical analysis. D.L.P. and VFAN are the guarantors of the paper.

\section{Conflicts of Interest}

The authors declare no conflict of interest.

\section{References}

1. Tenter, A.M.; Heckeroth, A.R.; Weiss, L.M. Toxoplasma gondii: From animals to humans. Int. J. Parasitol. 2000, 30, 1217-1258.

2. Montoya, J.G.; Liesenfeld, O. Toxoplasmosis. Lancet 2004, 363, 1965-1976.

3. Ferreira, M.S.; Borges, A.S. Some aspects of protozoan infections in immunocompromised patients - a review. Mem. Inst. Oswaldo. Cruz. 2002, 97, 443-457.

4. Lang, C.; Grob, U.; Luder, C.G.K. Subversion of innate and adaptative immune responses by Toxoplasma. gondii. Parasitol. Res. 2007, 100, 191-203.

5. Degerli, K.; Kilimcioğlu, A.A.; Kurt, Ö.; Tamay, A.T.; Özbilgin, A. Efficacy of azithromycin in a murine toxoplasmosis model, employing a Toxoplasma gondii strain from Turkey. Acta Trop. 2003, $88,45-50$.

6. Carruthers, V.B.; Suzuki, Y. Effects of Toxoplasma gondii infection on the brain. Schizophr. Bull. 2007, 33, 745-751.

7. Kaye, A. Toxoplasmosis: Diagnosis, treatment, and prevention in congenitally exposed infants. J. Pediatr. Health. Care. 2011, 25, 355-364.

8. Schmidt, D.R.; Hogh, B.; Andersen, O.; Hansen, S.T.; Dalhoff, K.; Petersen, E. Treatment of infants with congenital toxoplasmosis: Tolerability plasma concentrations of sulfadiazine and pyrimethamine. Eur. J. Pediatr. 2006, 165, 19-25. 
9. Haverkos, H.W. Assessment of therapy for toxoplasma encephalitis: The TE study group. Am. J. Med. 1987, 82, 907-914.

10. Rahman, M.A.; Mossa, J.S.; Al-Said, M.S.; Al-Yahya, M.A. Medicinal plant diversity in the flora of Saudi Arabia 1: A report on seven plant families. Fitoterapia 2004, 75, 149-161.

11. Emami, S.A.; Asgary, S.; Naderi, G.A.; Ardekani, M.R.S.; Aslani, S.; Airin, A.; Kasher, T.; Sahebkar, A. Investigation of antioxidant and anti-glycation properties of essential oils from fruits and branchlets of Juniperus oblonga. Rev. Bras. Farmacogn. 2012, 22, 985-993.

12. Hussain, A.I.; Anwar, F.; Rasheed, S.; Nigam, P.S.; Janneh, O.; Sarker, S.D. Composition, antioxidant and chemotherapeutic properties of the essential oils from two Origanum species growing in Pakistan. Rev. Bras. Farmacogn. 2011, 21, 943-952.

13. Moresco, H.H.; Queiroz, G.S.; Pizzolatti, M.G.; Brighente, I.M.C. Chemical constituents and evaluation of the toxic and antioxidant activities of Averrhoa carambola leaves. Rev. Bras. Farmacogn. 2012, 22, 319-324.

14. Kavitha, N.; Noordin, R.; Kit-Lam, C.; Sasidharan, S. Real Time Anti-Toxoplasma gondii Activity of an Active Fraction of Eurycoma. longifolia Root Studied by in Situ Scanning and Transmission Electron Microscopy. Molecules 2012, 17, 9207-9219.

15. Zhai, B.; Clark, J.; Ling, T.; Connelly, M.; Medina-Bolivar, F.; Rivas, F. Antimalarial Evaluation of the Chemical Constituents of Hairy Root Culture of Bixa. orellana L. Molecules 2014, 19, 756-766.

16. The World Health Organization (WHO). The World Health Report 1999: Making a difference; WHO: Geneva, Switzerland, 1999; pp. 31-63.

17. Oliveira, F.Q.; Andrade-Neto, V.; Krettli, A.U.; Brandão, M.G.L. New evidences of antimalarial activity of Bidens pilosa roots extract correlated with polyacetylene and flavonoids. J. Ethnopharmacol. 2004, 93, 39-42.

18. Silva, N.C.C.; Fernandes Júnior, A. Biological properties of medicinal plants: A review of their antimicrobial activity. J. Venom. Anim. Toxins. Incl. Trop. Dis. 2010, 16, 402-413.

19. Walton, N.J.; Mayer, M.J.; Narbad, A. Vanillin. Phytochemistry 2003, 63, 505-515.

20. Tai, A.; Sawano, T.; Yazama, F.; Ito, H. Evaluation of antioxidant activity of vanillin by using multiple antioxidant assays. BBA-Gen. Subjects. 2011, 1810, 170-177.

21. Fitzgerald, D.J.; Stratford, M.; Narbad, A. Analysis of the inhibition of food spoilage yeasts by vanillin. Int. J. Food. Microbiol. 2003, 86, 113-122.

22. Vaghasiya, Y.K.; Nair, R.; Soni, M.; Baluja, S.; Chanda, S. Synthesis, structural determination and antibacterial activity in compounds derived from vanillin and 4-aminoantipyrine. J. Serb. Chem. Soc. 2004, 69, 991-998.

23. Rakchoy, S.; Suppakul, P.; Jinkarn, T. Antimicrobial effects of vanillin coated solution for coating paperboard intended for packaging bakery products. As. J. Food. Ag-Ind. 2009, 2, 138-147.

24. Imanishi, H.; Sasaki, Y.; Matsumoto, K.; Watanabe, M.; Ohta, T.; Shirasu, Y.; Tutikawa, K. Suppression of 6-TG-resistant mutations in V79 cells and recessive spot formations in mice by vanillin. Mutat. Res. Lett. 1990, 243, 151-158.

25. Ohta, T.; Watanabe, M.; Watanabe, K.; Shirasu, Y.; Kada, T. Inhibitory effects of flavourings on mutagenesis induced by chemicals in bacteria. Food Chem. Toxicol. 1986, 24, 51-54. 
26. Ho, K.; Yazan, L.S.; Ismail, N.; Ismail, M. Apoptosis and cell cycle arrest of human colorectal cancer cell line HT-29 induced by vanillin. Cancer Epidemiol. 2009, 33, 155-160.

27. Nguyen, T.T..; Iwaki, A.; Ohya, Y.; Izawa, S. Vanillin causes the activation of Yap1 and mitochondrial fragmentation in Saccharomyces cerevisiae. J. Biosci. Bioeng. 2014, 117, 33-38.

28. Surjadinata, B.B.; Cisneros-Zevallos, L. Biosynthesis of phenolic antioxidants in carrot tissue increases with wounding intensity. Food. Chem. 2012, 134, 615-624.

29. Beaudry, F.; Ross, A.; Lema, P.P.; Vachon, P. Pharmacokinetics of vanillin and its effects on mechanical hypersensitivity in a rat model of neuropathic pain. Phytother. Res. 2010, 24, 525-530.

30. Timmerman, P.; Verboom, W.; Reinhoudt, D.N. Resorcinarenes. Tetrahedron 1996, 52, 2663-2704.

31. Machado, M.; Dinis, A.M.; Salgueiro, L.; Custódio, J.B.A.; Cavaleiro, C.; Sousa, M.C. Anti-Giardia activity of Syzygium aromaticum essential oil and eugenol: Effects on growth, viability, adherence and ultrastructure. Exp. Parasitol. 2011, 127, 732-739.

32. Ito, H.; Nakayama, T.; Sherwood, M.; Miller, D.; Ueda, M. Characterization and Lithographic Application of Calix[4]resorcinarene Derivatives. Chem. Mater. 2008, 20, 341-356.

33. Gunasekaran, S.; Ponnusamy, S. Vibrational spectra and normal coordinate analysis on an organic non-linear optical crystal-3-methoxy-4-hydroxy benzaldehyde. Indian. J. Pure. Ap. Phy. 2005, 43, 838-843.

34. Alonso Moreno, Y.; Trapero Quintana, Y.M. Toxicidad aguda oral de la o-vainillina. Rev. Cubana. Farm. 2008, 42, 0-0.

35. (OECD) Organization for Economic Cooperation and Development. Guidelines 423, Acute Oral Toxicity-Acute Toxic Class Method. In OECD Guidelines for Testing of Chemicals; OECD: Paris, France, 2001; pp. 1-14.

36. Clarke, G.; Ting, K.N.; Wiart, C.; Fry, J. High correlation of 2,2-diphenyl-1-picrylhydrazyl (DPPH) radical scavenging, ferric reducing activity potential and total phenolics content indicates redundancy in use of all three assays to screen for antioxidant activity of extracts of plants from the malaysian rainforest. Antioxidants 2013, 2, 1-10.

37. Mishra, K.; Ojha, H.; Chaudhury, N.K. Estimation of antiradical properties of antioxidants using DPPH assay: A critical review and results. Food Chem. 2012, 130, 1036-1043.

38. Yen, G.C.; Chen, H.Y. Antioxidant activity of various tea extracts in relation to their antimutagenicity. J. Agric. Food Chem. 1995, 43, 27-32.

39. Brand-Williams, W.; Cuvelier, M.E.; Berset, C. Use of a free radical method to evaluate antioxidant activity. LWT-Food. Sci. Technol. 1995, 28, 25-30.

40. Liu, D.; Sheng, J.; Li, Z.; Qi, H.; Sun, Y.; Duan, Y.; Zhang, W. Antioxidant activity of polysaccharide fractions extracted from Athyrium multidentatum (Doll.) Ching. Int. J. Biol. Macromol. 2013, 56, 1-5.

41. Wang, Z.; Luo, D. Antioxidant activities of different fractions of polysaccharide purified from Gynostemma pentaphyllum Makino. Carbohyd. Polym. 2007, 68, 54-58.

42. Barla, A.; Ozturk, M.; Kultur, S.; Oksuz, S. Screening of antioxidant activity of three Euphorbia species from Turkey. Fitoterapia 2007, 78, 423-425.

43. Zhao, T.; Zhang, Q.; Qi, H.; Zhang, H.; Niu, X.; Xu, Z.; Li, Z. Degradation of porphyran from Porphyra haitanensis and the antioxidant activities of the degraded porphyrans with different molecular weight. Int. J. Biol. Macromol. 2006, 38, 45-50. 
44. Azzi, A.; Davies, K.J.; Kelly, F. Free radical biology - terminology and critical thinking. FEBS Lett. 2004, 558, 3-6.

45. Makni, M.; Chtourou, Y.; Fetoui, H.; Garoui, E.M.; Boudawara, T.; Zeghal, N. Evaluation of the antioxidant, anti-inflammatory and hepatoprotective properties of vanillin in carbon tetrachloride-treated rats. Eur. J. Pharmacol. 2011, 668, 133-139.

46. Oliveira, T.C.; Silva, D.A.O.; Rostkowska, C.; Béla, S.R.; Ferro, E.A.V.; Magalhães, P.M.; Mineo, J.R. Toxoplasma gondii: Effects of Artemisia annua L. on susceptibility to infection in experimental models in vitro and in vivo. Exp. Parasitol. 2009, 122, 233-241.

47. Silva, T.A.C.; Chioccola, V.L.P. Toxoplasma gondii acute infection: Estimation of humoral response and blood parasitism in mice AS/n inbred. Sci. Med. 2010, 20, 88-92.

48. Dubey, J.P.; Lindsay, D.S.; Speer, C.A. Structures of Toxoplasma gondii tachyzoites, bradizoytes, and sporozoytes and biology and development of tissue cysts. Clin. Microbiol. Rev. 1998, 11, 267-299.

49. Sullivan, W.J.; Jeffers, V. Mechanisms of Toxoplasma Gondii persistence and latency. FEMS Microbiol. Rev. 2012, 36, 717-733.

50. McCarthy, S.M.; Davis, C.D. Prooxidant diet provides protection during murine infection with Toxoplasma gondii. J. Parasitol. 2003, 89, 886-894.

51. Rose, K.N.; Hardie, M.J.; Atwood, J.L.; Raston, C.L. Oxygen-center laden C2h symmetry resorcin[4]arenes. J. Supramol. Chem. 2001, 1, 35-38.

52. Tempone, A.G.; Treiger Borborema, S.E.; Andrade, H.F., Jr.; Amorim Gualda, N.C.; Yogi, A.; Salerno Carvalho, C.; Bachiega, D.; Lupo, F.N.; Bonotto, S.V.; Fischer, D.C.H. Antiprotozoal activity of Brazilian plant extracts from isoquinoline alkaloid-producing families. Phytomedicine 2005, 12, 382-390.

53. Ye, H.; Wang, K.; Zhou, C.; Liu, J.; Zeng, X. Purification, antitumor and antioxidant activities in vitro of polysaccharides from the brown seaweed Sargassum pallidum. Food Chem. 2008, 111, $428-432$.

Sample Availability: Samples of the compounds are available from the authors.

(C) 2014 by the authors; licensee MDPI, Basel, Switzerland. This article is an open access article distributed under the terms and conditions of the Creative Commons Attribution license (http://creativecommons.org/licenses/by/3.0/) 